\title{
Fibrosis quística en mama en jóvenes universitarias por medio de ultrasonografía
}

Griselda Vega-Cruz grisi2039@hotmail.com

Juan Manuel Sánchez-Soto sotojmss@yahoo.com.mx

Cristina Juárez Landín cjlandin@gnail.com

Mónica Celis Guzmán nsa89010@gmail.com

Universidad Autónoma del Estado de México

\section{RESUMEN}

Se realizó un estudio en universitarias del área de la salud de la Universidad del Estado de México, las edades de las participantes oscilan entre 19 a 24 años, aparentemente sanas. El objetivo fue, determinar la relación de proporción de fibrosis quística en mama, por medio de imágenes ultrasonográficas. Fue un estudio de corte transversal cualitativo, conformado por una muestra de 32 estudiantes femeninas. Los resultados son, el $65 \%$ presentó nódulos del tipo fibroadenoma y quistes de mama, de este porcentaje, el 100\% señalo haber utilizado hormonas para el control natal, 19.4\% utilizó levonorgestrel (Pildora anticonceptiva de emergencia) de forma recurrente, $12.5 \%$ tiene antecedentes heredo familiares y solo el $18 \%$ de la muestra indico que se realiza autoexploración mamaria. Una de las principales causas de la fibrosis quística, es el consumo de anticonceptivos hormonales, se le suma un estilo de vida poco saludable. Las participantes son estudiantes del área de la salud y durante su formación profesional, las universitarias han realizado actividades de promoción y educación para la salud sobre el cáncer de mama, por lo tanto, cuentan con los conocimientos para llevar a cabo la autoexploración, sin embargo, menos del 20\% se responsabiliza de su cuidado en la salud.

Palabras clave: mama; anticonceptivos hormonales; fibrosis quística 


\title{
Use ultrasonography for cyst fibrosis in breast \\ of young university
}

\begin{abstract}
The study was carried out in university students of the health area of the University of the State of Mexico. The range ages are 19 to 24 years old and appear to be healthy. The purpose of the research was to determine the ratio of cystic fibrosis in the breast, through ultrasonographic images. It is a qualitative cross-sectional study with a sample size of 32 individuals, using a sampling for convenience. The results found were that $65 \%$ had fibroadenoma-like nodules and breast cysts, of this percentage, 100\% reported using hormones for birth control, 19.4\% used levonorgestrel (Emergency Contraceptive Pile) recursively, $12.5 \%$ indicated having a family history, on the other hand, only $18 \%$ of the sample indicated that breast self-examination is performed. It is concluded that one of the main causes of cystic fibrosis is the use of hormonal contraceptives and added to this is an unhealthy lifestyle. It should be noted that the participants are students in the area of health and in the course of their professional training, university students have carried out health promotion and education on breast cancer, therefore, they have the knowledge to carry out self-exploration and less than $20 \%$ are responsible for their health care.
\end{abstract}

Keywords: breast; hormonal contraceptives; cystic fibrosis

Artículo recibido: 05 octubre. 2021 Aceptado para publicación: 02 noviembre 2021

Correspondencia: grisi2039@ hotmail.com Conflictos de Interés: Ninguna que declarar 


\section{INTRODUCCIÓN}

A nivel mundial el cáncer de mama es uno de los problemas más comunes, este representa el $16 \%$ de todos los tipos de cáncer que se presentan en el género femenino. Se estima que, en 2004 se presentaron 519000 mujeres por cáncer de mama, este problema de salud está considerado como una enfermedad que se presenta en mayor porcentaje en países del mundo desarrollado y el $69 \%$ de las defunciones por esa causa, se reportaron en países en desarrollo (Organizaciòn Mundial de la Salud, 2004).

La Asociación internacional de registros de cancer (IAREC), en el 2014 señala que, hay una gran variación en la incidencia, las tasas normalizadas por edad de hasta 99,4 por 100 000 en América del Norte, en Europa oriental, América del Sur, África, Australia y Asia occidental, se presentaron incidencias moderadas con tendencia a un incremento. La incidencia más baja se presentó mayormente en los países africanos, aun así, no estaban exentos de que se incrementará en la incidencia de cáncer de mama.

En el 2013, la tasa de mortalidad a nivel nacional, fue de 14.35 por cada 100 mil mujeres presentándose en edades tempranas, siendo la mínima de 20 años, el Distrito Federal ocupaba el segundo lugar con una tasa de mortalidad de 19.91 (Cervantes, R. 2015). Este problema de salud no cesa, sino que anualmente hay incremento, en este sentido, en el 2014 se registraron 11,372 casos nuevos y una incidencia de 22.56 por cada 100,000 habitantes mayores de 10 años, el registro de defunción del 2015 fue de 6,252 con una tasa de 18 defunciones por cada 100,000 mujeres, siendo Sonora (28.6), Nuevo León (26), Coahuila (25.7), Chihuahua (24.8), Cd. México (24.7) y Sinaloa (22.2), los estados con mayor índice de mortalidad (Centro Nacional de Equidad de Género y Salud Reproductiva, 2016). En el mismo año, la Sociedad Americana de Cáncer en Estados Unidos, indicó que el riesgo de cáncer de mama aumenta con la edad, es decir, se presentó un caso por cada 206 mujeres de los cero meses a los 39 años, 1 de cada 27 en mujeres de 40 a 59 años, 1 de 29 de 60 a 69 años y 1 de 15 de 70 y más años, globalmente es un porcentaje de $12.08 \%$ ( 1 de 8 mujeres) durante la vida (citado en Cervantes, R. 2015).

Los resultados para el 2016, fueron de 6,650 defunciones en mujeres con una tasa de 18.8 por cada 100,000 siendo el género femenino de 40 y más años la población más vulnerable. Para el 2017, aunque mínimo se puede percibir un incremento en la tasa de mortalidad, siendo el 18.9 y un egreso de 24 por cada 100 en mujeres de 20 años o más. En el 2018 se registraron 7257 defunciones por este tipo de problemas de salud. En 2019, 
el índice de mortalidad se incrementó en un 2.9\%, el 12.5 de cada 100,000 de las mujeres son afectadas. El incremento de esta problemática de salud, de acuerdo con el instituto Nacional de Salud Pública, se debe a la falta de una revisión médica con diagnóstico y tratamiento oportuno (Instituto Nacional de Estadística y Geografía, 2020; HernándezNájera, Cahuana-Hurtado, Ávila-Burgos, 2021; Instituto Nacional de salud pública, 2020).

Existen varios factores de riesgo del cáncer de mama, un factor predisponente al cáncer de mama, es la fibrosis quística, este, se presenta con mayor incidencia y prevalencia y se asocia con los cambios endocrinos la urbanización y la adopción de modos de vida occidentales, investigadores en el 2010 señalaron que el riesgo de presentar nódulos en mamas, se incrementa proporcionalmente y se asocia al tejido adiposo por el estado nutricional y a la acción de las hormonas (Osorio, Bello, Vega, 2020).

Los antecedentes familiares de cáncer de mama multiplican el riesgo por dos o tres. Algunas mutaciones, sobre todo en los genes BRCA1, BRCA2, se asocian a un riesgo muy elevado de ese tipo de cáncer. Sin embargo, esas mutaciones son raras y explican solo una pequeña parte de la carga total de cáncer mamario (Narod, Rodríguez, 2011). Los factores reproductivos asociados a una exposición prolongada a estrógenos endógenos, como una menarca precoz, una menopausia tardía y un primer parto cuando se presenta a una edad madura, Las hormonas exógenas también conllevan un mayor riesgo de cáncer de mama, por lo que las usuarias de anticonceptivos orales y de tratamientos de sustitución hormonal tienen más riesgo que las mujeres que no usan esos productos. La lactancia materna tiene un efecto protector (IARC, 2014).

El consumo de alcohol, el sobrepeso, la obesidad y la falta de actividad física son factores desencadenantes del cáncer de mama, Danaei y colaboradores señalan que el $21 \%$ de todas las muertes por cáncer de mama registradas en el mundo, están relacionados con los estilos de vida antes mencionados (Reynoso-Noverón, N.; Torres-Domínguez, 2017). La proporción es mayor, en países de ingresos altos (27\%), siendo el sobrepeso y la obesidad los factores más relevantes. En los países de ingresos bajos y medios, la proporción de cáncer de mama atribuibles a esos factores de riesgo fue del 18\%, y la falta de actividad física fue el factor determinante más importante (10\%).

La diferente incidencia del cáncer de mama en los países desarrollados y los países en desarrollo puede explicarse en parte por los efectos de la alimentación, unidos a la mayor 
edad del primer embarazo, el menor número de partos y el acortamiento de la lactancia (2001).

La ultrasonografía en los estudios de mama, permite mediciones tumorales precisas que permiten detectar tumores menores de $1 \mathrm{~cm}$ con el uso de transductores de alta frecuencia (10 MHz), medir su profundidad con precisión (Martínez Sánchez, 2010, Pina, et al., 2004, García y Terán, 2014, citados en Guevara, et al, 2015).

El cáncer de mama es el más común entre las mujeres en todo el mundo, pues representa el $16 \%$ de todos los tipos de cáncer que se presentan en la mujer.

La incidencia de esta enfermedad progresivamente va en aumento y las personas que sobreviven a este incidente presenta efectos secundarios a corto y largo plazo, por lo tanto, es necesario resaltar que una atención primaria donde se realice un diagnostico oportuno y eficaz permite y permitirá mejorar la situación de la presencia de factores de riesgo conocidos y los nódulos que se asocien cercanamente al cáncer de mama.

\section{MÉTODO}

El Presente trabajo es un estudio de corte Cualitativo, Transversal, no experimental de campo, en donde las variables de inclusión son Jóvenes entre 19 a 24 años de edad, aparentemente sanas, que deseen participar en el estudio y firmen la carta de consentimiento informado.

\section{Tamaño de la muestra}

El cálculo de tamaño de la muestra para una estimación de una proporción para un estudio de corte transversal se utiliza (Fuentelsaz, 2004): $n=\left(Z^{2} * p * q\right) / d^{2}$

La enfermedad fibroquística del seno, tiene incidencia oscila alrededor del $10 \%$ en mujeres menores de 34 años; durante los años menstruales es del $25 \pm 5 \%$ según la población (Monsonego, 1991), por lo que:

\section{El tamaño de la muestra}

- $\mathrm{n}=32$ mujeres.

- $\mathrm{p}=0.25$

- $\mathrm{q}=0.75$ con un nivel de confianza de 0.95

- $Z=1.96$ y un error máximo admitido de 0.07 .

El muestreo se realizó por conveniencia. 


\section{Técnica de recolección de imágenes}

La técnica ecográfica realizada se llevó a cabo con el equipo de ultrasonografía SonoScape S2/S2BW, imagen 2D, visualizada con transductor lineal de 5-12 MHz. Tomando en cuenta distintos umbrales de edad.

\section{La exploración se realizó en dos fases:}

La primera es la exploración de la mama, diferenciando y evaluando la presencia de lesiones visibles y palpables en los cuatro cuadrantes de forma circular utilizando el dedo índice, medio y anular haciendo una ligera presión y finalizando en el área del pezón, al llegar a este punto se debe tomar el pezón con el dedo pulgar e índice y presionar para reportar la salida o no de secreciones repitiendo el mismo procedimiento en el otro seno. En la segunda fase comenzamos la identificación, proyectando la imagen con el ultrasonido y el transductor visualizando toda la parte anatómica de la mama para hallar irregularidades. En cada campo visualizado se realiza captura de imagen para obtener datos significativos como lo son, longitud, altitud y volumen de abscesos y/o quistes según sea el caso respectivamente. Con respecto a los Aspectos éticos los estudios realizados los estudiantes firmaron una carta de consentimiento informado en donde se les informa el objetivo, el procedimiento y la confidencialidad de los datos.

\section{RESULTADOS}

La muestra a la cual se le realizó el estudio fueron estudiantes del área de la salud las cuales cuentan con los conocimientos de las enfermedades crónico degenerativas con una edad promedio de 21.3 años de edad y una desviación estándar de 3.11, los reportes de la historia clínica se describen a continuación.

Se reporta el inicio de vida sexual activa a una edad de 13 años con un promedio 2.53 parejas sexuales.

Solo el 18\% de la muestra reporta el realizarse autoexploración de mama, a pesar de que el total cuenta con los conocimientos de cómo efectuar la exploración y han realizado promoción y educación para la salud a población estudiantil universitaria y a la comunidad abierta relacionada con el cáncer de mama.

El 9.2\% presentan antecedentes familiares de cáncer de mama y el $4.3 \%$ de cáncer cérvico uterino. De 32 pacientes incluidas, en 21 se demostraron nódulos fibroadenoma y quistes de seno, visualizados por ultrasonido de los cuales se pudo observar que prevaleció la 
alteración hormonal por causa de algún método anticonceptivo y el alto consumo de levonorgestrel (Pildora anticoncetiva de emergencia). (Cuadro 1).

Como ejemplos tenemos: nódulos anecoicos, con morfología ovoidea, orientación paralela, margen circunscrito, lesión interfase abrupta y sin características acústicas con un diámetro de $1 \mathrm{~cm}$. Refiriéndose el consumo de píldoras anticonceptivas desde hace más de un año hasta la fecha actual.

Cuadro 1. Tabla de pacientes (21) Fibrosis Quística

\begin{tabular}{|l|c|}
\hline \multicolumn{1}{|c|}{ Método anticonceptivo } & Porcentaje \\
\hline Implante subdérmico & $14.28 \%(3)$ \\
\hline Inyecciones hormonales & $4.76 \%(1)$ \\
\hline Píldora anticonceptiva de Emergencia & $19.04 \%(4)$ \\
\hline Píldoras anticonceptivas & $14.28 \%(3)$ \\
\hline Condón & $38.09 \%(8)$ \\
\hline DIU mirena & $9.52 \%(2)$ \\
\hline
\end{tabular}

En las siguientes figuras se reportan los hallazgos encontrados por los USG.
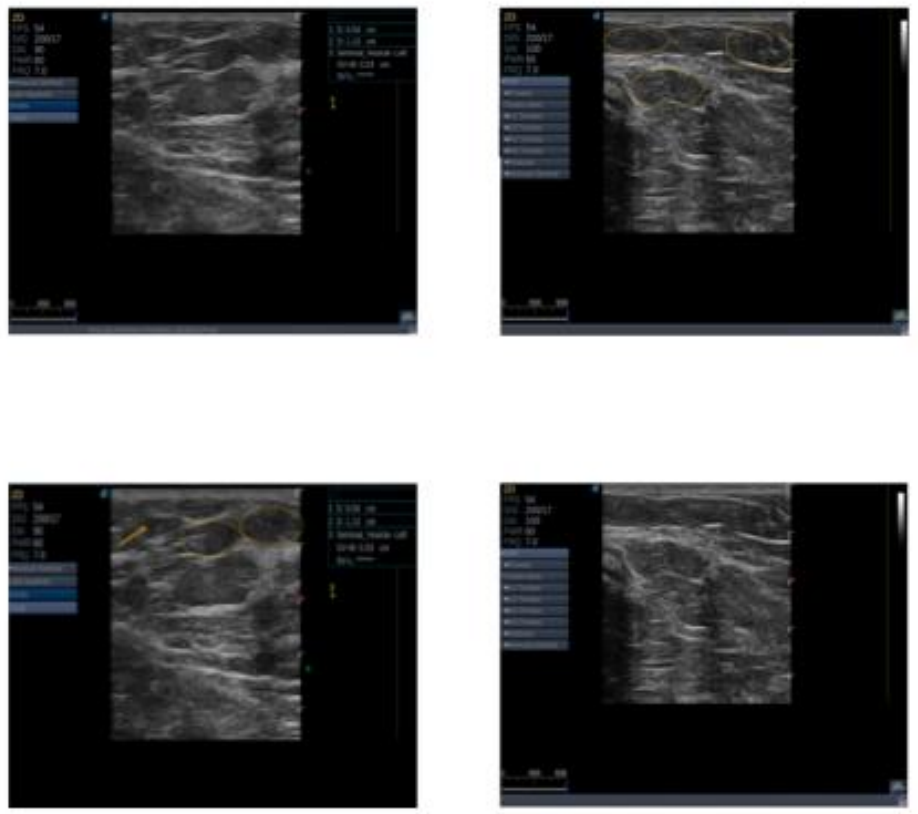

Figura 1. Mujer de 21 años sin antecedentes heredo familiares presentas tres fibromas en mama derecha de no reporta uso de hormas, lesiones epiteliales en tórax y mamas ocasionada por uso de brasear 
Fibrosis quística en mama ...
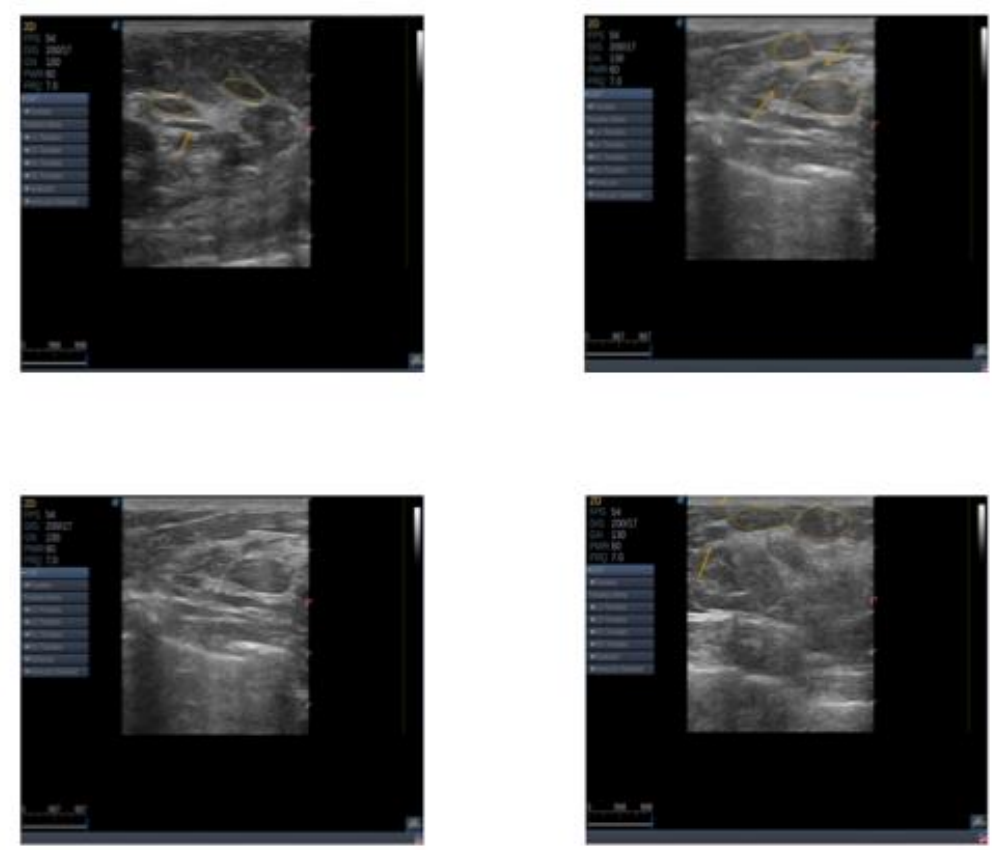

Figura 2. Mujer de 20 años de edad sin antecedentes heredo familiares, presentando dos fibromas en mama izquierda y cuatro en mama derecha, reporta uso de píldoras anticonceptivas durante dos meses, lesiones epiteliales en tórax y mamas ocasionadas por uso de brasear.
Figura 3. Mujer de 20 años con antecedente de cáncer de mama, presenta dos fibromas en mama izquierda, reporta el uso de implante por más de un año, lesiones epiteliales en tórax por uso de brasear.
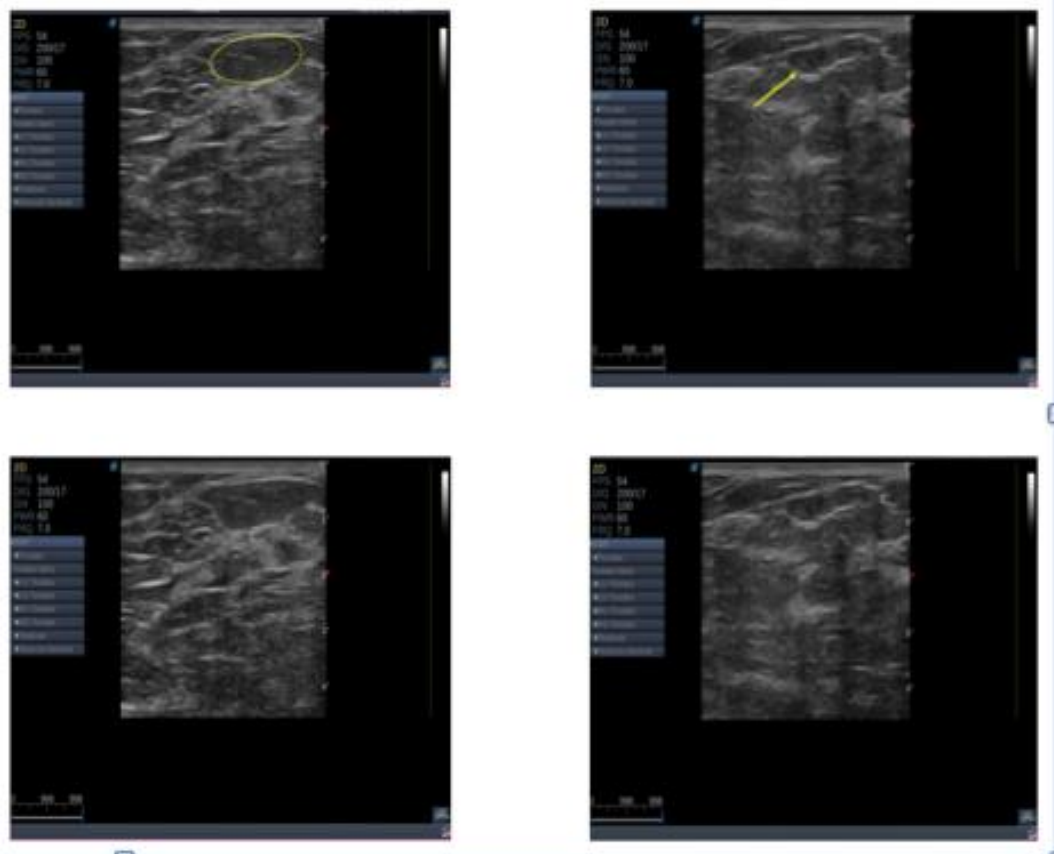

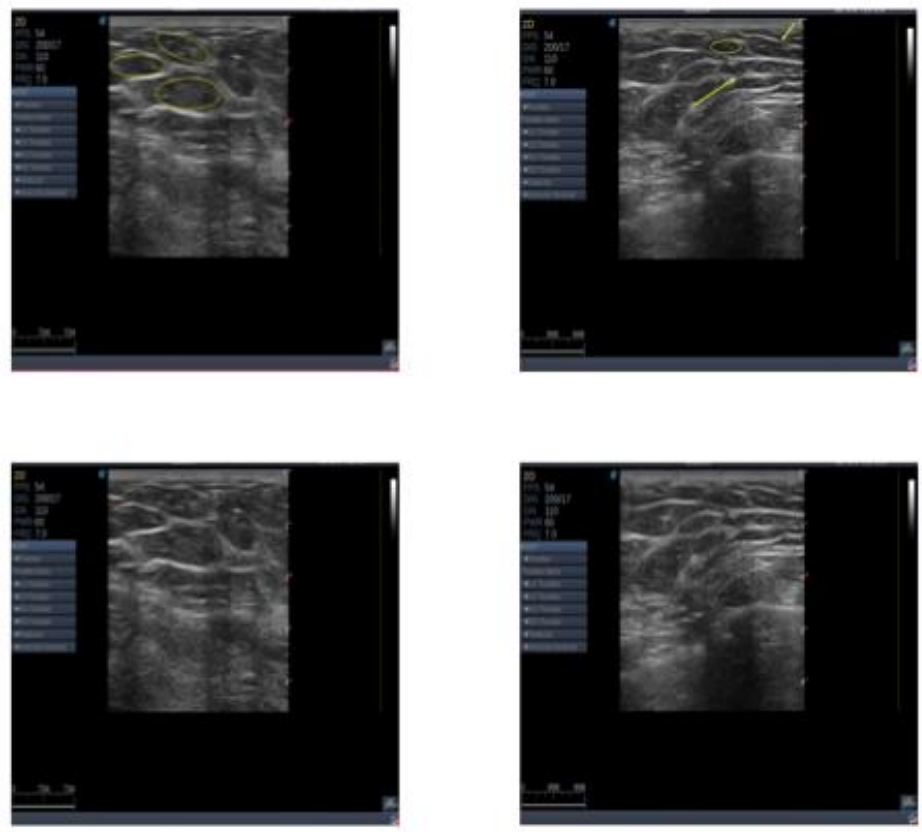

Figura 4. Mujer de 19 años sin antecedentes heredo familiares, presenta un fibroma en mama derecho y uno en mama izquierda, reporta el uso de la píldora de emergencia en dos ocasiones.

Figura 5. Mujer de 20 años de edad, sin antecedente heredo familiar, presenta dos fibromas en mama izquierda y uno en mama derecha, reporta uso de píldora anticonceptiva en dos ocasiones, sin presencia de lesión epitelial.
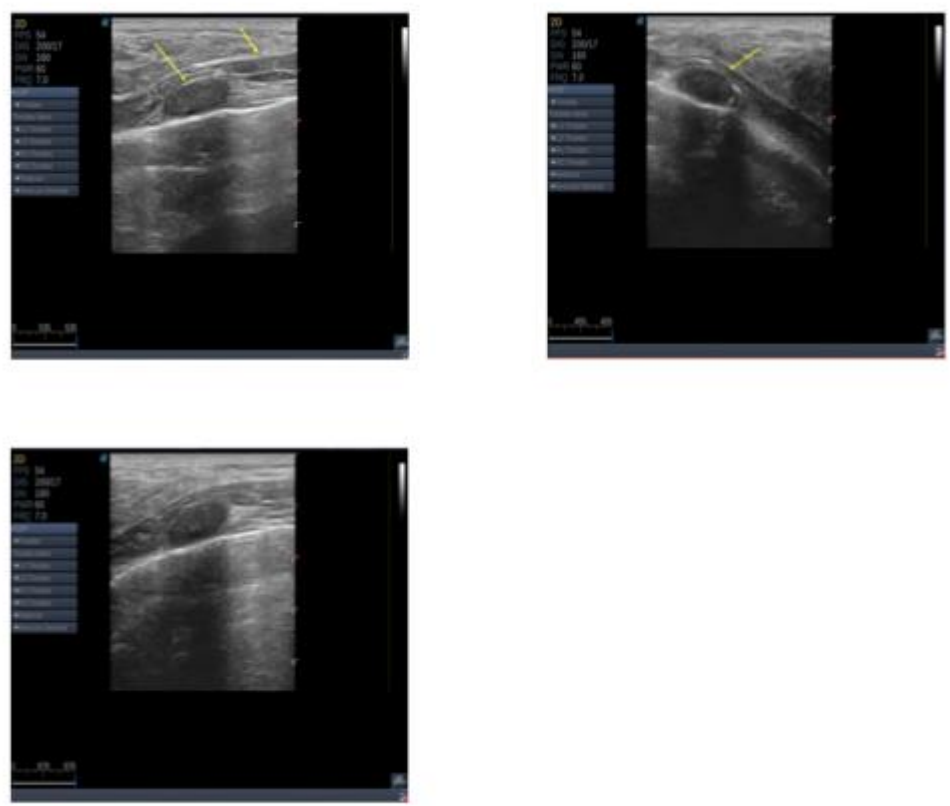
Fibrosis quística en mama ...
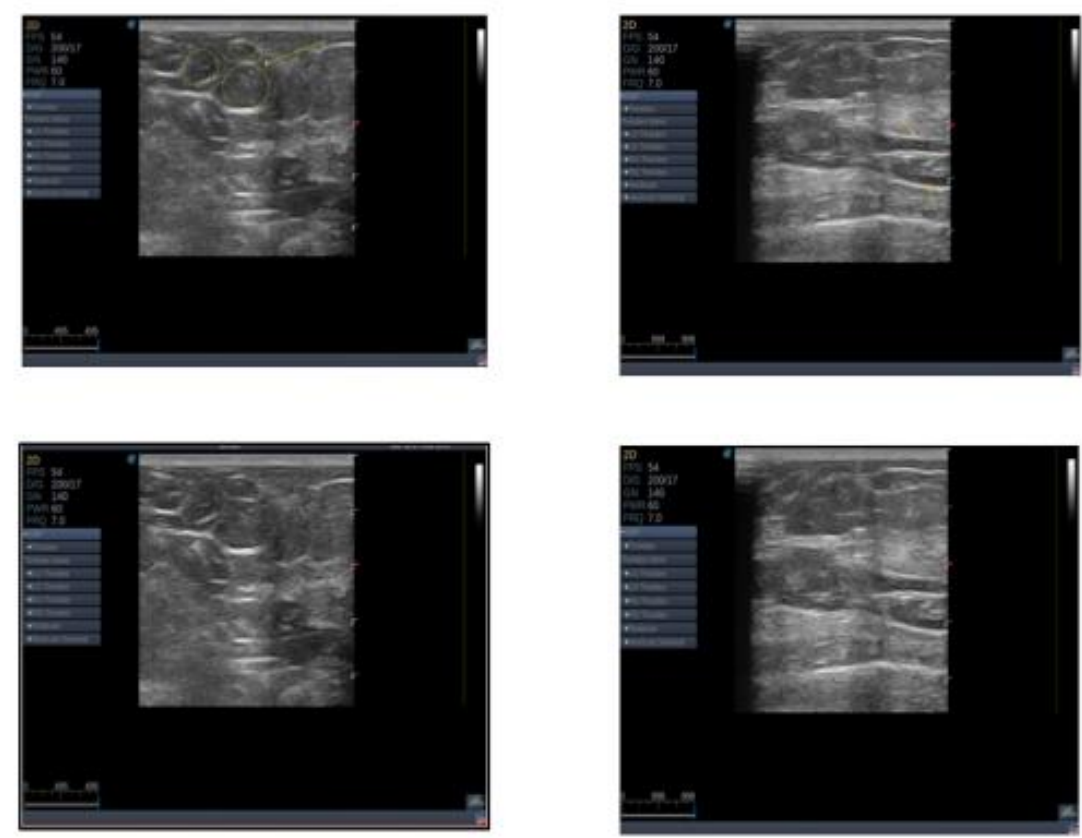

Figura 6. Mujer de 22 años de edad sin antecedentes heredo familiares, presentando un fibroma en mama derecha y dos fibromas en mama izquierda, reporta uso de condón, sin presencia de lesión epitelial.

\section{DISCUSIÓN}

En los últimos años la salud preventiva es primordial, la educación para la salud, promoción de la salud, son áreas que permiten trabajar en un cambio de conducta y el autocuidado. La incidencia y prevalencia de las enfermedades crónico degenerativas tienen un gran impacto a la salud y a edades más tempranas, por lo tanto, se pone mayor atención a este tipo de patologías para evitar una complicación, como es el caso del cáncer de mama (Pérez, Álvarez, Selva, Guilarte, y Pérez, 2011)

Torres-Mejía, et al. En el 2009, señalan que el uso y exposición continua de hormonas esteroideas, hace que la mujer sea más vulnerable para desarrollar cáncer de mama, lo que lleva a predisponer que los métodos anticonceptivos hormonales, pueden repercutir sobre la mama, caso similar a lo encontrado en el estudio, donde el $100 \%$ de las estudiantes que presentaron fibromas, reportan el consumo de hormonas para el control natal, ocasionando en la mama una influencia neurohormonal.

En las imágenes radiológicas hay diversidad de interpretaciones, para Peck y Lowman, la mama se hace radiográficamente más densa, con dilataciones de los galactóforos e imágenes de tipo quístico, principalmente cuando el anticonceptivo es de predominio estrogénico, como se puede observar en el 100\% de las imágenes reportadas en el presente trabajo. Un factor muy importante en que un $25 \%$ presento desarrollo de tubérculos de 
Montgomery bastante marcado, donde se podría diferenciar con el caso de una mujer lactante, se habla de mujeres sin ninguna gestación, estos procesos anatomopatológicas de mamas sometidas a anticonceptivos hormonales recuerdan a las que presentan las mamas gestantes y lactantes: aumento de la celularidad en el epitelio lobulillar, aparición de secreción en la luz de los acini y duetos, y, en general, aumento del volumen y de la actividad parenquimatosa; si bien estas modificaciones descritas no están generalizadas a toda la mama, como en las gestantes y lactantes, apareciendo sólo en focos localizados (Herrero, 1987).

Los anticonceptivos hormonales y el uso frecuente de la píldora de emergencia como ya mencionado tienden a responsabilizarse en la alteración congénita, fibrosis quística en mamas. Sin embargo, se demuestra que el $34.3 \%$ de mujeres que no están sometidas a ningún método anticonceptivo hormonal no presentan ningún caso de alteración congénita.

La OMS ubica el cáncer como la causa principal de mortalidad a nivel mundial y plantea en su informe que la incidencia de este podría aumentar en un 50\% hasta el año 2020. Se menciona que a partir de ahí habría 15 millones de nuevos casos.

El cáncer de mama es la primera causa de muerte por tumores en las mujeres mexicanas, con un promedio de 10 decesos al día. En los últimos 10 o 20 años en México los fallecimientos por esta enfermedad han aumentado, mientras que en Europa y Estados Unidos han disminuido considerablemente, afirmaron integrantes del Instituto de Investigaciones Biomédicas (Romero, 2018).

Entre los factores de riesgo de Cáncer de mama más estudiados, están los reproductivos, como la edad de la menarquia y menopausia, edad al primer embarazo, número de embarazos, uso de anticonceptivos y terapia hormonal (TH), y la práctica de lactancia materna (LM). Aunque se ha demostrado una asociación de algunos de estos factores con la neoplasia, el efecto del uso de los anticonceptivos hormonales.

Se realizó encuesta a las 32 mujeres de las cuales de ahí se determina que debido a su incidencia y prevalencia mundial y por los innumerables avances a la tecnología, el número de casos diagnosticados en cáncer de mama aumenta cada vez más. Sin embargo, diariamente se puede observar los avances tecnológicos y la salud preventiva y el autocuidado, permiten una detección oportuna y efectiva en etapas tempranas a través de estudios de imagen cribados. 
Uno de las acciones fundamentales para la prevención del cáncer de mama y que deben realizar los profesionales de la salud, es el autocuidado, Prado, González, Paz y Romero $(\mathrm{S} / \mathrm{F})$, señalan que el autocuidado son acciones que el individuo debe llevar a cabo para beneficiar la salud, el bienestar y la calidad de vida en este sentido, el ultrasonido permite una detección oportuna y es de suma importancia, ya que nos permite demostrar lesiones como, fibromas, quistes, y evitar que las lesiones lleguen a ser de mayor diámetro o palpables en caso de neoplasias.

\section{AGRADECIMIENTO}

El presente trabajo, ha sido financiado por el Consejo Mexicano de Ciencia y Tecnología (COMECYT), con folio EESP2021-0026 y me brinda la oportunidad de estar en este proyecto de investigación titulado "Sistema Inteligente para diagnóstico de alteraciones de fibrosis quística (6249/2020 CIB)" y que se realiza en la Universidad Autónoma del Estado de México.

\section{REFERENCIAS BIBLIOGRÁFICAS}

Asociación Americana de Cáncer (2019). Factores de riesgo del cáncer de seno.

Asociación internacional de registros de Cáncer, (2014). Planificación y desarrollo de registros de cáncer de base poblacional en los países de ingresos bajos y medios. Recuperado de https://publications.iarc.fr/Book-And-Report-Series/IarcTechnical-Publications/Planificaci\%C3\%B3n-Y-Desarrollo-De-Registros-DeC\%C3\%A1ncer-De-Base-Poblacional-En-Los-Pa\%C3\%ADses-De-Ingresos-

Bajos-Y-Medios-2014, consultado el 25 de agosto de 2021.

Bedoya, A., López, A., Cardona-Arias, J. Factores de riesgo para el cáncer de mama. (2019). Revista Cubana de Obstetricia Ginecología. vol. 45(2).

Centro Nacional de Equidad de Género y Salud Reproductiva (2016). Información Estadística Cáncer de Mama. Recuperado de https://www.gob.mx/salud/cnegsr/acciones-y-programas/informacionestadistica-cancer-de-mama. consultado el 21 de junio de 2021.

Cervantes, R. (2017). Comportamiento de mortalidad de cáncer de mama de acuerdo a edad en el IMSS Querétaro en el periodo 2008-2015. Tesis inédita para obtener el grado de maestría (internet), recuperado de http://ring.uaq.mx/bitstream/123456789/1548/1/RI005046.pdf. consultado el 21 de junio de 2021. 
Guevara, G., Quintas, M., González, H., Rodríguez, O., Valdivia, D. \& García, D. (2015). Eficacia de la ecografía mamaria en la estadificación pre-quirúrgica del cáncer de mama.

MEDICIEGO.

No.4.

Recuperado

de https://www.medigraphic.com/pdfs/mediciego/mdc-2015/mdc154b.pdf.

Consultado el 09 de octubre de 2021

Hernández-Nájera O, Cahuana-Hurtado L, Ávila-Burgos L. (2021) Costos de atención del cáncer de mama en el Instituto de Seguridad y Servicios Sociales de los Trabajadores del Estado, México. Revista de Salud Publica 63:538-546.

Herrero, A. (1987) Anticoncepción y mama. Revista de senología y patología mamaria. Instituto Nacional de Estadística y Geografía (2020). Estadísticas a propósito del día mundial de la lucha contra el cáncer de mama, 19 de octubre. Recuperado https://www.inegi.org.mx/contenidos/saladeprensa/aproposito/2020/Cancermam a20.pdf). Consultado el 20 de junio de 2021, disponible en

Instituto Nacional de salud pública (2020). Cáncer de mama, una prioridad para la salud de las mexicanas. Recuperado https://www.insp.mx/avisos/5090-octubre-cancermama-19.html. Consultado el 13 de julio de 2021].

Narod, S. \& Rodríguez, A. (2011). Predisposición genética para el cáncer de mama: genes BRCA1 y BRCA2. Salud Pública de México, 53(5), pp. 420-429.

Navarro-Ibarra, M., Caire-Juvera, G., Ortega-Vélez, M., Bolaños-Villar, A., \& SaucedoTamayo, M. (2015). Influencia de los factores reproductivos, la lactancia materna y la obesidad sobre el riesgo de cáncer de mama en mujeres mexicanas. Nutrición Hospitalaria, 32(1),291-298.

Osorio, N., Bello, C. \& Vega, L. (2020). Factores de riesgo asociados al cáncer de mama. Revista Cubana de Medicina General Integral, núm. 2

Organización Mundial de la Salud, (2004). Cáncer. Recuperado de https://www.who.int/es/news-room/fact-sheets/detail/cancer . Consultado el 13 de julio de 2021.

Pérez, G., Álvarez, J., Selva, A., Guilarte, O., y Pérez, R. (2011) Actividades educativas en mujeres con factores de riesgo de cáncer de mama. MEDISAN vol.15, n.6

Peto J. (2001) Cancer epidemiology in the last century and the next decade. Nature. $17 ; 411(6835): 390-5$ 
Prado, L., González, M., Paz, N. \& Romero K. (2014). La teoría Déficit de autocuidado: Dorothea Orem punto de partida para calidad en la atención. Recuperado de http://scielo.sld.cu/pdf/rme/v36n6/rme040614.pdf. Consultado el 10 de octubre de 2021

Reynoso-Noverón, N.; Torres-Domínguez, J. (2017). Epidemiología del cáncer en México: carga global y proyecciones 2000-2020 Revista Latinoamericana de Medicina Conductual / Latin American Journal of Behavioral Medicine, vol. 8, núm. 1, pp. 9-15

Romero, A. (2018). Aumenta en México la mortalidad por cáncer de mama. Recuperado de https://www.gaceta.unam.mx/aumenta-en-mexico-la-mortalidad-por-cancerde-mama/. Consultado el 21 de agosto de 2021.

Torres-Mejía, G., \& Ángeles-Llerenas, A. (2009). Factores reproductivos y cáncer de mama: principales hallazgos en américa latina y el mundo. Salud Pública de México, 51, pp.165-171. 